\title{
Household financial burden associated with health care for older people in Viet Nam: A cross-sectional survey
}

Nguyen Hoang Giang ( $\nabla$ nguyengiang@hspi.org.vn )

Health Strategy and Policy Institute https://orcid.org/0000-0002-4944-2825

Nguyen The Vinh

Health Strategy and Policy Institute https://orcid.org/0000-0002-6908-261X

Hoang Thi Phuong

Health Strategy and Policy Institute https://orcid.org/0000-0002-9773-8241

Nguyen Thi Thang

Health Strategy and Policy Institute

Tran Thi Mai Oanh

Health Strategy and Policy Institute https://orcid.org/0000-0003-0823-9668

\section{Research Article}

Keywords: Financial burden, catastrophic health expenditure, financial distress, out-of-pocket health expenditure, older people, Viet Nam

Posted Date: December 28th, 2021

DOI: https://doi.org/10.21203/rs.3.rs-1197537/v1

License: (c) (i) This work is licensed under a Creative Commons Attribution 4.0 International License. Read Full License 
1 Household financial burden associated with health care for older people in Viet Nam: A

2 cross-sectional survey

3 Nguyen Hoang Giang ${ }^{1}$, Nguyen The Vinh ${ }^{1}$, Hoang Thi Phuong ${ }^{1}$, Nguyen Thi Thang ${ }^{1} \&$ Tran Thi

$4 \quad$ Mai Oanh ${ }^{1}$

$5 \quad{ }^{1}$ Health Strategy and Policy Institute, Hanoi, Viet Nam

6 Corresponding author: Nguyen Hoang Giang, Health Strategy and Policy Institute, Lane 196, Ho

7 Tung Mau Street, Mai Dich Ward, Cau Giay District, Hanoi, Viet Nam

9 Abstract

\section{Background}

11 Population ageing and the associated increase in the health care needs of older people are

12 putting pressure on the health care system in Viet Nam. The country prioritizes health care for

13 older people and has developed financial protection policies to mitigate financial hardship due

14 to out-of-pocket health expenditures (OOPHEs) borne by their households. This study examines

15 the level and determinants of the financial burden of OOPHE among households with people

16 aged $\geq 60$ years in Viet Nam.

\section{Methods}

18 A cross-sectional household survey was conducted among a sample of 1536 older people living

19 in 1477 households in three provinces representing the North, Central and South regions of Viet

20 Nam during 2019-2020. The financial outcomes were catastrophic health expenditure (CHE), 
21 using the World Health Organization's definition, and financial distress due to OOPHE.

22 Multivariate binary logistic regression analysis was employed to determine the factors associated

23 with these outcomes.

\section{Results}

25 OOPHE for older household members accounted for $86.3 \%$ of total household health

26 expenditure. Of households with older people, 8.6\% (127) faced $\mathrm{CHE}$, and $12.2 \%$ (181)

27 experienced financial distress due to OOPHE. Households were at a higher risk of incurring

28 financial burdens related to health expenditures if they had fewer household members; included

29 only older people; were in rural or remote, mountainous areas; and had older members with

30 noncommunicable diseases. There was no significant association between health insurance

31 coverage and financial burden. However, when older people sought tertiary care or private care,

32 the possibility of a household facing CHE increased. Regardless of the type and level of care,

33 health service utilization by older people results in a higher likelihood of a household 34 encountering financial distress.

\section{Conclusions}

36 This study reveals that OOPHE for older people can impose substantial financial burdens on

37 households, leading them to face $\mathrm{CHE}$ and financial distress. This study provides evidence to

38 justify reforming financial protection policies and introducing policy interventions targeted at

39 better protecting older people and their households from the financial consequences of OOPHE.

40 There is also the need to strengthen the grassroots health facilities to provide primary care closer

41 to home at lower costs, particularly for the management of noncommunicable diseases. 
42 Keywords: Financial burden, catastrophic health expenditure, financial distress, out-of-pocket

43 health expenditure, older households, Viet Nam

44 


\section{Background}

49 According to United Nations estimates, the number of people aged $\geq 60$ years will soar from

50901 million in 2015 to 2.1 billion (or $21 \%$ of the world's population) by 2050 [1]. While increases

51 in life expectancy are a positive population outcome, population ageing generates many

52 challenges to productivity and economic growth and may threaten social security systems [2].

53 For health systems, an increasing population of older adults might negatively affect progress

54 towards providing universal health coverage - that is, ensuring people's access to essential

55 health services and protecting them from financial hardship [3]. If health service coverage and

56 financial assistance are inadequate, older persons are at a higher risk of being exposed to

57 catastrophic and impoverishing health expenditures. Because older people have greater and

58 more diverse health care needs, they suffer the dual burden of deteriorating earnings and

59 multiplying out-of-pocket health expenditures (OOPHEs) [4].

60 Viet Nam is a lower-middle-income country experiencing rapid population ageing. The

61 percentage of older people, who are $\geq 60$ years, in the population will rise from $12.3 \%$ in 2020 to

$6226 \%$ in 2050 [5], which will also bring about an increase in health care needs for the older

63 population. A national study showed that about $70 \%$ of older people reported that they had poor

64 health status, and more than one third (37.4\%) reported having had an acute illness or injury

65 during the past year [6]. The study also found that a high proportion of older persons reported

66 having a chronic noncommunicable disease (NCD), and on average, each older person suffered

67 from three conditions [6]. Moreover, older people account for $88 \%$ of the burden of NCDs in Viet

68 Nam[7]. Such statistics indicate that the older population has high health care needs, especially 
69 for comorbidities and chronic NCDs requiring long-term treatment, thus resulting in high costs

70 for individuals, families and society.

71 To address the care needs of its ageing population, the government of Viet Nam prioritizes health

72 care for older people through various laws and regulations. The health sector has implemented

73 initiatives to improve their access to services and protect people, including older adults, from

74 financial hardship due to health care costs. According to the Health Insurance Law, all people

75 aged $\geq 80$ years are entitled to a $100 \%$ subsidy of their health insurance premium. Health

76 insurance coverage is also fully subsidized for those aged 60-79 years who live in poor

77 households or belong to ethnic minority groups, while those living in near-poor households are

78 entitled to a $70 \%$ discount on their health insurance premium. Pensioners who worked in the

79 formal sector) and retired at 60 years of age are entitled to free health insurance enrolment as

80 part of their retirement benefits.

81 Viet Nam has successfully expanded health insurance coverage to more than $90 \%$ of its

82 population, including, by 2018 , to nearly $95 \%$ of all older persons [8]. Despite this progress,

83 OOPHE remains high, accounting for nearly 50\% of total health expenditure in 2017 [9]. The high

84 OOPHE is both a financial barrier, hampering people's access to health care, and the reason for

85 the financial consequences faced by their households. In 2011, the Viet Nam National Ageing

86 Survey found that about half of older persons with illness did not receive any treatment [6]. The

87 most common reason given was the lack of money to pay for services [6].

88 Although some research has been conducted to determine the financial burden of health

89 spending, there has been no detailed investigation in Viet Nam of the financial burden of health

90 expenditure among households that include older people. A study using data from the Viet Nam 
91 Household Living Standards Survey, conducted every 2 years, from 2002 to 2010 revealed that

92 the proportion of households suffering from catastrophic health expenditures (CHEs) and

93 impoverishment due to health care costs, respectively, ranged from $3.9 \%$ to $5.7 \%$ and from $2.5 \%$

94 to $4.1 \%$ [10]. Despite the availability of these data, these indicators have not been assessed in

95 relation to households with older persons, nor there has been an analysis of the extent to which

96 older persons contribute to a high household burden of OOPHE and which types of services they

97 received. Another study of older Vietnamese adults living in a rural area showed that older people

98 with chronic conditions spent significantly more on health care than those without these diseases

99 [11]. However, this study was carried out on a small scale and at the individual level. Furthermore,

100 previous studies have not considered detailed components of out-of-pocket spending to try to

101 understand how much older people have to pay for various health care services and the extent

102 to which they have to rely on financial coping strategies, such as borrowing money from relatives

103 or friends. To fill such gaps in the literature, this study aims to assess the level of financial burden

104 and identify factors associated with financial outcomes due to health care spending among 105 households in Viet Nam that include older people.

107 Methods

108 Household survey

109 This cross-sectional household survey was conducted from November 2019 to August 2020 in 110 three provinces representing Viet Nam's North, Central and South regions, namely Yen Bai, Thanh 111 Hoa and Tien Giang. 
112 A total of 1536 older people aged $\geq 60$ years was selected using multistage cluster sampling. The

113 study first divided districts into urban and rural strata in each province and then randomly chose

114 one district from each stratum. In each district, two communes were randomly selected as

115 sampling clusters; therefore, 12 communes were chosen in total. After the communes were

116 determined, the lists of older people residing in each commune were gathered from the local

117 Provincial Population Centres (12 lists). From the list for each commune, older people were

118 divided into three age groups (60-69, 70-79 and $\geq 80$ years), which formed three separate

119 sampling frames. As the predefined cluster size was 128 per commune, the number of

120 participants selected in each age group within a cluster was randomly selected using

121 proportionate random sampling. This means the distribution of age groups in each cluster was

122 identical to the actual age distribution in the corresponding commune.

123 As the sampling units are older people and randomly selected, there was a case where more than

124 one eligible respondent lived in the same household. No selected participants refused to take

125 part in the study; however, 182 people were ineligible for inclusion because they were deaf or

126 mute or had impaired cognitive function, based on responses to the Mini-Cog tool (a score of $\leq 4$

127 points) [12]. In these cases, new participants were chosen randomly from the list of unselected

128 older persons to represent the same sex and age group. Therefore, the final sample was 1536

129 older people living in their own homes in 1477 households in the study sites during the survey.

130 Data collection

131 Face-to-face interviews using a structured questionnaire were undertaken among the study

132 participants. The research team developed the questionnaire, comprising mainly questions to 133 elicit information about health status, health care utilization and corresponding spending on 
134 health. In addition, the survey tool collected information about other household members'

135 demographic and socioeconomic characteristics, their health service use, associated health

136 payments, and household assets and housing conditions.

137 Local commune-based health workers were recruited to conduct the interviews. All interviewers

138 attended a 2-day training workshop that included information about the questionnaire,

139 interviewing skills and data confidentiality; the trainees also conducted some pilot interviews

140 before the actual survey.

141 At the home visit, interviewers met directly with the eligible older people. Moreover, one adult

142 household member was nominated as the most knowledgeable individual regarding the

143 household's general information and health care issues; in some cases, the older person also

144 provided the general household information. To ensure the quality of the data, members of the

145 study team acted as field supervisors. The supervisors directly observed some of the first

146 interviews and provided feedback. Random and unannounced spot-check visits were also

147 undertaken.

148 Health care setting

149 Viet Nam's health service delivery system uses a public-private mix in which the public sector

150 takes the dominant role in service provision, especially for specialist and inpatient care. The

151 health system is divided into four levels that correspond to the country's administrative divisions:

152 commune, district, provincial and central. In each province, there are a provincial-level general

153 hospital and several specialist hospitals. At the district and commune levels, a district hospital

154 and commune health stations (one per commune) provide primary health care services for the 
155 population in their catchment areas. At the community level, private health providers are well

156 established, including polyclinics and specialist clinics, which provide outpatient services for local

157 people. Local pharmacies are also readily available in the community, allowing people to

158 purchase a broad range of medications, from over-the-counter to prescription medicines,

159 including vitamins, painkillers, antibiotics and medications for chronic diseases, such as

160 hypertension and diabetes.

161 Yen Bai is a mountainous province located in northwest Viet Nam, with a population of 0.82

162 million, of whom nearly $60 \%$ are ethnic minorities [13]. The province has only one private hospital

163 [14]. The second site, Thanh Hoa, has approximately 3.7 million residents, with 76\% living in rural

164 areas [13]. Eleven provincial public hospitals serve this north-central province, and health care

165 in the private sector is well developed and includes 12 private hospitals [14]. Tien Giang province

166 is situated in the Mekong Delta region of southwest Viet Nam. There are approximately 1.7

167 million people, with $77 \%$ of the population living in rural areas [13]. Only one private hospital

168 serves this province [14].

169 Variables

170 Outcome variables

171 The study outcomes were the financial burden linked to OOPHE borne by households that include

172 at least one person aged $\geq 60$ years. The household-level financial outcomes were constructed

173 using two indicators: CHE and financial distress. These measurements have been widely used to

174 reflect the financial consequences of OOPHE by households [15-18]. 
175 In this study, household OOPHE was defined as direct spending on health care made by

176 individuals and households, including an individual's health expenses incurred at the time of

177 service, such as health insurance co-payments, direct medical expenses (e.g. medications,

178 laboratory tests, consultation fees), direct non-medical expenses associated with accessing

179 health services (e.g. food, transportation and accommodation) and other non-medical expenses

180 (e.g. informal gifts for health providers). OOPHE also encompasses home care for older members

181 that is paid for by households, self-medication and the purchase of medical devices. However, it

182 does not include any prepayments for health services, for example, in the form of taxes or specific

183 insurance premiums or contributions and, where possible, it is net of any reimbursements to

184 individuals who made the payments.

$185 \mathrm{CHE}$ is defined as OOPHE for care that exceeds a certain threshold of household resources during 186 a given period [19]. In this study, the World Health Organization's approach was used to

187 calculate $\mathrm{CHE}$, which determines that a household is facing $\mathrm{CHE}$ when its total OOPHE is $\geq 40 \%$ of 188 its capacity to pay [20]. The household's capacity to pay was calculated by subtracting food 189 expenditure from total household expenditures. Additionally, to ensure comparability with 190 recent studies employing the financial protection outcomes of the Sustainable Develop Goals 191 (Indicator 3.8.2), we estimated the proportion of households with catastrophic spending on 192 health care as a share of total household expenditure at $10 \%$ and $25 \%$ thresholds [21].

193 Financial distress due to spending on health was defined as financial activities or coping strategies

194 employed by households to finance the cost of inpatient and outpatient services, for example, 195 by borrowing money from friends or relatives, taking out loans from banks or other lenders, or 
196 selling assets. A binary outcome indicator was used for financial distress to indicate which

197 households employed coping strategies to finance spending on health.

\section{Covariates}

199 Covariates were selected based on a review of the relevant literature and the availability of data.

200 The independent variables were constructed as household-level data. Such variables included

201 the characteristics of the head of household (i.e. being aged $\geq 60$ years, sex, ethnicity, educational

202 level and occupational status) and the household (i.e. household size, the number of older people

203 in the household, the presence of at least one child younger than 6 years), the composition of

204 the household (i.e. a household with only older people versus a household with more than one

205 generation), living in a rural area versus an urban area, and the province of residence.

206 The variable of household health insurance status was also created with two categories: fully

207 insured (i.e. all households members have health insurance) and not fully insured (at least one

208 member does not have health insurance).

209 In this study, a wealth index was used as a proxy indicator of the household's living standards.

210 Following Filmer and Pritchett [22], principal component analysis was undertaken to construct

211 an asset score for each household according to household assets and durable products, the

212 materials used for housing construction, the water source, type of toilet facility and ownership

213 of agricultural land. Furthermore, the index was adjusted to reflect the relationship between

214 living standards and properties in urban and rural areas [23]. The wealth index was categorised

215 into quintiles $(\mathrm{Q} 1, \mathrm{Q} 2, \mathrm{Q} 3, \mathrm{Q} 4$, and $\mathrm{Q} 5)$. The poorest quintile (Q1) represents the $20 \%$ of

216 households lowest on the wealth index, and the fifth quintile represents the $20 \%$ that were 
217 highest on the wealth index. To reflect the existence of NCDs among the population, households

218 were divided into three categories based on the number of comorbidities affecting the key older

219 respondent (No NCD, $1 \mathrm{NCD}, \geq 2 \mathrm{NCDs}$ ).

220 To account for the association between health spending and the level and type of care, we

221 generated variables related to health service utilization by older people. The use of such variables

222 is justified by prior studies in low- and middle-income countries that indicated certain types of

223 care were significant predictors of health-related financial outcomes [24-27]. These were created

224 as continuous variables distinguished by type of care (outpatient versus inpatient, public versus

225 private), type of health facility (using commune- or district-level care as primary health care and

226 including tertiary care and private care). The variables were: (i) outpatient care, defined as the

227 total number of outpatient visits made by the older household member during the past 12

228 months divided by the number of older household members; and (ii) inpatient care, defined as

229 the total number of inpatient admissions for the older household member during the past 12

230 months divided by the number of older household members interviewed.

\section{Statistical analysis}

232 The unit of analysis was households with older adults. We used descriptive analytics for the

233 socioeconomic characteristics of the households, health care utilization by older household

234 members, the breakdown of OOPHE for older household members and the household financial

235 hardships experienced due to these expenditures. We analysed differences in CHE and financial

236 coping strategies by household characteristic using the $t$-test, $\chi^{2}$ test and analysis of variance for

237 statistical significance. We also used a multivariate logistic regression model for binary variables

238 to explore determinant effects on CHE and the financial distress of households. Backwards 
239 elimination was employed to identify the best set of predictors, as shown by descriptive analytics.

240 The goodness-of-fit for the models was examined using a likelihood-ratio test, the Akaike

241 information criterion and the Bayesian information criterion. The variance inflation factor was

242 used to check multicollinearity, and a factor of $<10$ was considered acceptable. All analyses were

243 performed by using Stata 13 statistical software (StataCorp, College Station, Texas, USA).

\section{Ethical approval}

245 The scientific and ethical aspects of the study were reviewed and approved by the Institutional

246 Scientific Research Committee of the Health Strategy and Policy Institute, Hanoi. Ethical approval

247 was also obtained from the Research Ethics Review Committee of the World Health Organization

248 (protocol no. ERC.0003085). Local health authorities issued permission to conduct the field 249 survey in their respective districts and provinces. All respondents were enrolled voluntarily and 250 provided both verbal and written informed consent.

\section{Results}

\section{Characteristics of the study households}

254 Among the 1477 sampled households, there was a balanced distribution of urban and rural 255 populations. The average household size was 3.2 persons, with $15.6 \%$ (231) of households

256 including children younger than 6 years and $56.5 \%(835)$ including more than one person aged

$257 \geq 60$ years. In $42.2 \%$ (624) of households, people aged $\geq 60$ years lived alone or only with their

258 spouse. Moreover, $92.6 \%$ (1367) of heads of household were aged $\geq 60$ years, $53.1 \%$ (784) were 
259 men and $98.7 \%$ (1449) were members of the Kinh ethnic group. One third of heads of household

260 had completed at least high school, and two thirds were not currently working.

261 In terms of health care, $79.4 \%$ (1173) of households had at least one older person who had one

262 or more NCDs. The mean number of monthly outpatient visits per older person at grassroots

263 health facilities was 0.46 , at tertiary facilities was 0.36 and at private health facilities was 0.13 .

264 During the previous 12 months, the mean number of inpatient admissions per older person per

265 household was higher at tertiary hospitals (0.19 visits) than at district hospitals (0.09) and private

266 health providers (0.02) (Table 1 ).

267

268 Incidence of catastrophic health expenditure and financial distress

269 Table 2 shows the estimates of OOPHE borne by households that included at least one older

270 person. On average, each household spent nearly 8 million Vietnamese dong ( US\$350) on

271 health care during the previous 12 months. OOPHE for older household members contributed

272 most to total household health expenditure, accounting for $86.3 \%$. Significantly, $8.6 \%$ (127) of

273 households had OOPHE that exceeded $40 \%$ of their capacity to pay. When health spending for

274 older household members was removed from total household health expenditures, the

275 corresponding figure was only $1.96 \%$ (29). Using definitions of CHE found in the Sustainable

276 Development Goals, the percentages of households with OOPHE exceeding $10 \%$ of total

277 household expenditure was 7.5\%; and 1.8\% exceeded 25\% of total household expenditure.

278 The proportion of households suffering financial distress due to OOPHE was $12.3 \%$ (181).

279 Households used different coping strategies to finance spending on health care for older 
280 household members. Of those experiencing financial distress, 31\% (56/181) of households had

281 to borrow money from relatives or friends; $25 \%$ (45) got a loan from other individuals or agents,

282 such as moneylenders; and 4\% (7) sold property. More than one third of households used their

283 savings to pay for health care (data not shown).

\section{Descriptive statistics}

285 Table 3 shows the numbers and percentages of households experiencing CHE, according to the

286 two different standards, and financial distress, as measured by household-level covariates.

287 Using the CHE threshold of $40 \%$ of non-food expenditure, the highest incidence of CHE was seen

288 among the households in Yen Bai province (16.6\%; 82 households), followed by those in Thanh

289 Hoa (7\%; 35 households) and Tien Giang (1.9\%; 9 households). CHE was more prevalent among

290 households with fewer members $(P<0.001)$; without a child younger than 6 years; with only

291 older people (18.9\% versus $0.9 \%$ for others); with older members suffering from an NCD $(8.9 \%$

292 for 1 NCD and $11.1 \%$ for $\geq 2$ NCDs versus $2.6 \%$ of households without an older person with an

293 NCD; $P<0.001)$; with heads aged $\geq 60$ years who had completed at least secondary school $(11.5 \%$

294 for secondary school and $9.5 \%$ for high school or higher; $P=0.002$ ) or who were pensioners

295 (11.1\%; $P=0.037)$. Surprisingly, the incidence of CHE was higher in fully insured households than

296 in households that were not fully insured (9.4\% versus $2.3 \% ; P=0.002)$. Regarding health service

297 utilization, households that incurred CHE had older members with higher numbers of outpatient

298 visits at private health facilities and inpatient admissions to tertiary hospitals than households

299 not incurring CHE. 
300 When $\mathrm{CHE}$ at a $10 \%$ threshold of total household expenditure was assessed, we observed the

301 same patterns of bivariate associations as when the World Health Organization's definition was

302 used, except for health care service utilization by older household members. Compared with

303 households not facing $\mathrm{CHE}$, those experiencing $\mathrm{CHE}$ had older adults with significantly higher

304 numbers of outpatient visits and inpatient admissions at all levels of care, except for outpatient

305 visits to primary health care services.

306 In terms of coping with financial difficulties related to spending on health care, $15.2 \%$ of 307 households reported financial distress in Yen Bai, 11.4\% in Tien Giang and 10.2\% in Thanh Hoa.

308 The incidence of financial distress was significantly higher among those in the lower wealth

309 quintiles (Q1: 14.9\%; Q2: 14.9\%; Q3: 13.5\%) than among those in the better-off groups (Q4: 8.5\%;

310 Q5: 9.5\%). Notably, households that had older members with NCDs had higher rates of financial

311 distress (1 NCD: $11.9 \%$ and >NCDs: $17.5 \%$ ) than those without older members with NCDs (2\%).

312 Moreover, financial distress was significantly associated with higher utilization of most types of

313 care, except for inpatient admission to private health facilities.

\section{Determinants of financial burden due to health expenditure}

315 Table 4 presents the results of the multivariate logistic regression models identifying the 316 determinants of $\mathrm{CHE}$ and financial distress. The models indicate that household size, the presence

317 of older members with NCDs, the province of residence and utilization of outpatient and 318 inpatient services were significantly associated with CHE and financial distress resulting from 319 OOPHE. 
320 The results show that larger households were less likely to suffer $\mathrm{CHE}$ (odds ratio $[\mathrm{OR}]=0.18$ ) and

321 financial distress $(O R=0.89)$ compared with smaller households. Households in which older

322 people had at least one NCD were much more likely to experience CHE and financial distress than

323 households in which older people did not have an NCD (ORs ranging from 4.72 to 7.05).

324 Furthermore, households residing in the mountainous province (Yen Bai) had a higher risk of

325 facing financial catastrophe and distress due to health expenditure than their counterparts in

326 Tien Giang. Households in Thanh Hoa also had a higher likelihood of having CHE than those in

327 Tien Giang. Households headed by pensioners were less likely to suffer financial distress than

328 households in which the head was currently unemployed. Surprisingly, households in the higher

329 wealth quintiles were more likely to face CHE than those in the lowest quintiles (ORs ranging

330 from 2.84 to 7.89). Additionally, rural households were twice as likely to experience CHE as their

331 urban counterparts.

332 Older people's health service utilization was strongly correlated with the household's financial

333 burden resulting from OOHE. Households in which older adults had more frequent outpatient

334 visits at private health facilities had a higher risk of CHE. In addition, households with older

335 members who were hospitalized at a provincial or central hospital had a higher risk of facing CHE.

336 Furthermore, all of the variables related to health service utilization were significantly associated

337 with financial distress. These results indicate that regardless of the type and level of care, the

338 more frequently that older household members use health services, the higher the risk that

339 households will encounter financial distress due to health spending. 


\section{Discussion}

342 To the best of our knowledge, this is the first study to examine the magnitude and determinants

343 of financial burdens linked to OOPHE borne by households that include older adults in Viet Nam.

344 The study shows that households that include older people faced CHE and financial distress as

345 economic consequences of OOPHE made to provide care for their older members. Furthermore,

346 the demographic and socioeconomic characteristics of households and health service utilization

347 by older people were significant predictors of the financial hardship suffered in this study. The

348 results of this study can contribute towards gaining a better understanding of whether current

349 financial protection policies for older people work and which older populations are more

350 financially vulnerable and should be targeted for help by future policy interventions.

351 The study revealed that a considerable proportion of households with older people suffer from

352 CHE. Using the $40 \%$ threshold of non-food household expenditure, the incidence of CHE was $8.6 \%$

353 among households with older people, which was higher than corresponding figures for the

354 general population reported in prior studies in Viet Nam [10, 15]. Furthermore, older people, 355 especially those with chronic NCDs, require regular health care and, consequently, must 356 repeatedly pay for this care. In a previous study analysing national data collected from 2002 to

3572010 , the rates of CHE ranged from 3.9\% to 5.7\% [10]. Notably, the present study found that the

358 health spending for older household members accounted for most of a household's total

359 expenditure on health, at $86.3 \%$. Such findings imply that having older people in a household

360 predispose it to financial catastrophe. This contention is widely supported by evidence from

361 previous studies in Viet Nam [10, 24, 28] and low- and middle-income countries [29-32]. Using

362 data from the Viet Nam Household Living Standards Survey, two studies concluded that the 
363 presence of older adults in a household was significantly correlated with higher rates of CHE [10, $36428]$.

365 Another important finding is that $12.2 \%$ of the households facing financial distress due to health 366 expenditures to provide care for older people exceeded their family's resources. The households 367 that could not pay for services using cash on hand employed coping strategies to finance 368 health care costs for their older members, such as borrowing money from others, borrowing from 369 moneylenders or agents [33], and even selling assets [34]. Evidence of such coping mechanisms 370 undertaken by Vietnamese households to deal with unaffordable health care costs has been 371 identified in previous studies, and it includes options such as taking out high-interest loans, selling 372 assets, reducing daily consumption of foods and other neccesities and even forgoing expenses

373 for children's education [24, 33, 35, 36]. Similar to the findings in this study, previous studies in 374 low- and middle-income countries have demonstrated that households with older members and 375 with members who have chronic conditions are more likely to use coping strategies to ensure 376 their welfare following the use of health services [37-39]. This study is consistent with other 377 studies that showed borrowing from family or friends and taking out loans are the most common 378 forms of distress financing $[16,34,40]$. In Viet Nam, older people are well connected with their 379 family, friends, and communities [32]; thus, social networks seem to be important sources of 380 financial support $[41,42]$.

381 Households with older people seem to bear multiple financial burdens associated with their use 382 of health care services. First, using a significant proportion of a household's resources on health 383 care for older people may lead households to reduce the family's consumption of food and other 384 daily necessities, and even to a deterioration in living standards [33, 43]. Most older Vietnamese 
385 people have not participated in the formal labour force and, consequently, receive limited social 386 welfare benefits [6]. In our study, only one third of older people currently received retirement 387 benefits. Additionally, because of physical limitations due to ageing, they have less ability to 388 generate income and contribute to the family's resources [44].

389 Studies consistently have indicated that, by using these coping strategies to finance their OOPHE, 390 households may successfully address their short-term financial hardship but possibly increase 391 their economic susceptibility in the long run [16, 37, 38, 45]. A previous study by Thuy and 392 colleagues found that Vietnamese households often take out loans to repay current medical 393 debts and this exacerbates their existing financial constraints, which become harder to escape 394 [33]. Similarly, Wagstaff and colleagues found that many households in China take on new debt 395 while already in debt for medical care [46]. Moreover, since many older people are not able to 396 care for themselves or independently attend health facilities, other family members have to take 397 time off work to be with them. Consequently, households may bear noticeable indirect costs 398 related to the loss of productivity and income by caregivers through work missed while caring for 399 older household members [11,33].

400 In this study, $96.8 \%$ of all older adults had health insurance, and in $88.2 \%$ of households, everyone 401 had health insurance. One of the crucial objectives of having a health insurance policy is to 402 mitigate the financial consequences of OOPHE, particularly among disadvantaged and vulnerable 403 populations, such as older people, the poor and rural residents $[47,48]$. Despite the households 404 sampled having proportionally higher coverage of health insurance than households nationally, 405 the incidence of $\mathrm{CHE}$ among households with older people was more significant than that among 406 the general population. Further, the study did not find a significant association between health 
407 insurance coverage and financial outcomes for either $\mathrm{CHE}$ or financial distress. These findings

408 complement those of earlier studies in Viet Nam, showing that the current health insurance

409 system does not effectively protect households from the financial burden of health care spending

$410[10,24,49,50]$. As highlighted in a recent study of the population with NCDs, although having

411 health insurance is associated with greater health service utilization, health insurance was not a

412 determinant of CHE and financial distress [24].

413 These results are in agreement with those observed in prior studies in other countries where

414 health insurance schemes are not well designed and do not protect their beneficiaries from

415 economic hardship $[32,51,52]$. For example, studies have shown that Chinese health insurance

416 programmes had undesirable outcomes and did not protect the insured from financial

417 catastrophic and medical impoverishment, especially the older population $[30,53]$ and those with

418 NCDs $[54,55]$. There are several possible explanations for these findings. First, studies have

419 shown that co-payments for health insurance, even those that are only a small part of the total

420 treatment cost, can cause financial difficulty for patients, particularly those who are in low-

421 income groups $[56,57]$. In some cases, insured patients decided not to use their insurance

422 because of the costs of co-payment or because medicines covered by their health insurance were

423 not available at the time of service [24]. Second, as argued by Yip and Hsiao, the design of China's

424 health insurance scheme ignores the type of disease, and the health spending pattern results in

425 a negligible protective effect against CHE [51]. Du and colleagues contended that unfavourable

426 outcomes associated with health insurance schemes may be caused by the high burden of

427 chronic conditions among the older population and their associated health expenditure patterns

428 [58]. Third, limitations on benefit packages that fail to consider the health needs of financially 
429 vulnerable groups could partially explain the weak performance of insurance systems [59]. This

430 points to the need to redesign health insurance systems to better protect populations from the

431 economic burden of health expenditures, particularly older populations and disadvantaged

432 groups.

433 One interesting finding is that health service utilization at tertiary health facilities and private 434 health providers led to higher odds of households with older people suffering CHE. These results

435 reflect those of our earlier observations among Vietnamese households with members who had 436 NCDs [24]. In Viet Nam, although the same medical procedures or services are provided in both 437 district and provincial hospitals, the fees for services delivered in higher-level facilities are higher 438 than those for the same services offered at the lower levels, and the insured also has higher co439 payments for services at higher-level facilities. Recent studies have highlighted gaps in the 440 capacities of primary care health facilities, particularly commune health stations, to provide 441 essential health services for the community owing to factors such as inappropriate financial 442 mechanisms, poor quality and quantity of medicines, lack of equipment and health care staff, 443 and a weak health information system [60-63]. These constraints lead to the underutilization of 444 health services at primary care facilities where insured patients are less likely to incur co445 payments and additional out-of-pocket spending. Weraphong and colleagues suggested that 446 bypassing or underusing designated primary care facilities can lead insured patients to utilize 447 private care and public providers outside their local areas, which increases their non-medical and 448 indirect costs and may potentially push households into financial catastrophe and 449 impoverishment [64]. Moreover, the current study found that, regardless of the type or level of 450 care, health service utilization by older household members resulted in a higher possibility of a 
451 household encountering financial distress related to spending on health care. Given that almost

452 all older people in our sample were insured, this association is notable but not surprising because

453 the weak financial protection function of Viet Nam's health insurance system has been broadly

454 discussed $[10,24,49,50]$.

455 Multivariate regression analyses showed significant associations between key household 456 characteristics and the financial burden of health expenditures. This study indicates that smaller

457 households are more likely to suffer CHE and financial distress than households with more 458 members. A possible explanation for this might be that households of only older people and with 459 fewer members had fewer people to contribute income and, consequently, had limited financial 460 resources; thus, they may be at a higher risk of financial hardship [31]. Notably, nearly half of 461 households in this study consisted of only older people living on their own or with their spouse. 462 This finding aligns with those observed in China, Nigeria $[31,65,66]$ and also in Viet Nam $[10$, 463 67]. In China, several studies consistently found that empty-nest households consisting of older 464 people living alone had greater odds of incurring CHE than those in which an older person lived 465 with a spouse or in a multigenerational household $[65,66]$. These findings might further suggest 466 the need to implement a financial protection policy that can lower the risk of financial burden for 467 households with only older people.

468 This study confirms the high prevalence of NCDs among the older population, as found in 469 previous studies in Viet Nam $[6,11]$. The presence of older people with NCDs in a household was 470 a strong predictor of $\mathrm{CHE}$ and financial distress. Furthermore, households where older people

471 had NCDs were seven times more likely to incur CHE compared with households in which older 472 people had no NCDs. These findings broadly support the work of other studies and emphasize 
473 the economic burden of NCDs for households $[39,68]$ and particularly among older households

$474[11,30,69]$. Patients with chronic NCDs require more frequent health services; therefore, they 475 are more likely to repeatedly incur OOPHE than those without NCDs [11, 24, 70]. In a multicountry

476 study, Lee and colleagues demonstrated that NCD multimorbidity is highly correlated with a more

477 regular use of health services and a higher economic burden for the population [70]. As suggested

478 in the literature, households in which older members with NCDs seek regular care also incur more

479 direct non-medical costs (e.g. transportation, food and accommodation for patients and 480 caregivers) [71-73] and indirect costs (e.g. income loss as caregivers take time off from work) [11,

481 33]. The findings of this study strengthen the evidence for the poor performance of the existing

482 health financing system in protecting households from the negative economic impact of NCDs, 483 particularly those households with older people.

484 The current study also found that older households residing in rural areas or in Yen Bai (a remote, 485 mountainous province) have a higher likelihood of incurring CHE than those living in urban and 486 lowland areas (i.e. Tien Giang). These results are in keeping with those of Minh and colleagues 487 who found, through a secondary analysis of 10 years of national data, that living in a rural area is 488 linked with a higher risk of CHE [10]. Similar findings have also been reported from other 489 countries [74], such as China [53] and India [68]. This implies that households that include older 490 people living in low-resource settings are more financially vulnerable than their counterparts 491 residing in more socioeconomically advantaged areas. This further highlights the need for policies 492 that are better targeted towards households with older people who are living in rural and remote, 493 mountainous areas because these households are at greater risk of suffering financial 494 catastrophe as a result of health care use. 
495 It is somewhat surprising that older households in the higher wealth quintiles are more likely to 496 face CHE than those in the lowest quintile. This is contrary to the findings of prior studies in other 497 countries that found low-income households with older people have a higher risk of financial 498 hardship due to health expenditure than higher-income households [30, 31, 53]. Several factors 499 could explain this observation. First, poor households may not spend much out of pocket due to 500 their limited resources, while better-off households spend more on health services. Likewise, 501 other studies have reported that wealthier households incur more OOPHE than poorer 502 households $[32,75]$. Second, there is evidence that poor people, even those with health 503 insurance, simply do not access institutional care because of the health insurance co-payment, 504 associated non-medical costs and indirect costs. Instead, they may resort to self-medication or 505 forgo treatment because of the expected costs; however, this may cause more severe health 506 complications and lead to further financial difficulties in the future $[16,76]$. The data from our 507 study show that poor households used self-medication more often and less outpatient and 508 inpatient care compared with higher-quintile households. Therefore, further qualitative 509 investigation is needed to understand the health care-seeking behaviour of older people and 510 coping mechanisms used in response to the need to pay for health care.

511 Finally, several important limitations of this study need to be acknowledged. First, this study used 512 self-reported data on health service use, OOPHE and NCDs; thus, the data are subject to recall 513 bias. Second, the findings are limited by the cross-sectional design, making it impossible for us to 514 draw causal interpretations of the associations. Given that Viet Nam has plans to improve 515 financial protection for its population, further longitudinal studies may help assess the causal 516 impact of such policy interventions on health service utilization and financial outcomes among 
517 the targeted populations. Finally, the study collected information about OOPHE using

518 disaggregated items by illness episode, while aggregated items about OOPHE were used to collect

519 data about health spending for other family members. Evidence has indicated that a lower degree

520 of disaggregation of out-of-pocket items results in an underestimate of the mean OOPHE [77].

\section{Conclusions}

523 In response to the increased need for health care among older people, the government of Viet

524 Nam has been gradually developing policies that aim to improve older people's access to

525 health care services and protect them from financial consequences linked to health service

526 utilization. Although the limited impact of existing financial protection policies in Viet Nam has

527 been widely discussed in the literature, the current study appears to be the first to investigate

528 the financial burden of OOPHE on the older population and their households. The findings

529 provide critical confirmation that Vietnamese households are more likely to experience $\mathrm{CHE}$ and

530 financial distress as a result of paying for health care for older household members.

531 The results of the regression analyses identified certain factors that make these households more

532 financially vulnerable than others. In particular, households are at a higher risk of incurring

533 financial burdens related to health expenditures if they are smaller; include only older people;

534 are in rural or remote, mountainous areas; and have older household members with NCDs.

535 Consistent with prior studies in Viet Nam, this study did not find a meaningful relationship

536 between having health insurance and financial burden. Furthermore, having older household

537 members who sought care at private providers and more-specialized hospitals increased the 
538 possibility of a household facing CHE. Regardless of the type and level of care, health service

539 utilization by older people results in a higher likelihood that a household will experience financial

540 distress related to spending on health. Our findings show that the current social health insurance

541 scheme, which aims to protect beneficiaries against financial difficulties, seems not to have

542 achieved its policy objective, particularly for older people.

543 The findings of this study have a number of important implications for policy development.

544 International experience suggests that the implementation of health insurance alone will not 545 directly decrease OOPHE: reform also needs to be undertaken of the health financing 546 mechanisms linked to the health insurance system [78]. Redesigning benefit packages to target

547 and prioritize the needs of older people is recommended, particularly aiming to help those with

548 chronic NCDs and those in disadvantaged groups, such as poor people and those living in rural

549 and remote areas. For example, the health insurance programme might consider waiving co-

550 payments for older adults with chronic conditions who require long-term treatment with

551 medicines. Further research could examine the distribution patterns of the costs of health

552 services for older people as an initial step towards developing a comprehensive and financially

553 protective service package for older adults. Moreover, another strategy could be to reform

554 provider payment mechanisms to control overprescribing and service abuse while enhancing the

555 use of primary health care services and discouraging more-expensive hospital-based care. Finally,

556 it is also strongly recommended that primary health care facilities be strengthened so that care

557 can be provided closer to home at lower costs, particularly for the management of NCDs.

\section{List of abbreviations}


559 OOPHE: out-of-pocket health expenditure

560 CHE: catastrophic health expenditure

561 NCD: noncommunicable disease

562 OR: odds ratio

563

\section{Declarations}

565 Ethics approval and consent to participate The scientific and ethical aspects of the study were

566 reviewed and approved by the Institutional Scientific Research Committee of the Health

567 Strategy and Policy Institute, Hanoi. Ethical approval was also obtained from the Research

568 Ethics Review Committee of the World Health Organization (Protocol No. ERC.0003085). Local

569 health authorities issued permission to conduct the field survey in their respective districts and

570 provinces. All respondents were enrolled voluntarily and provided both verbal and written

571 informed consent. 


\section{Consent for publication Not applicable}

573 Availability of data and materials The data that support the findings of this study are available

574 from the Health Strategy and Policy Institute, but restrictions apply to the availability of these

575 data, which were used under license for the current study, and so they are not publicly available.

576 However, data are available from the authors upon reasonable request and with permission of

577 the Health Strategy and Policy Institute.

578 Competing interests The authors declare that they have no competing interests.

579 Funding This research was funded by the World Health Organization Centre for Health

580 Development (WHO Kobe Centre: K18024). Publication costs were also funded by the Centre.

581 The Centre did not contribute to the design of the study, data collection, analysis, interpretation

582 of data or the writing of this manuscript. However, staff at the Centre reviewed the draft of this 583 manuscript.

584 Authors' contributions GN (Nguyen Hoang Giang) and VN (Nguyen The Vinh) were responsible 585 for analysing the data. The first draft of the paper was written by GN, VN, Nguyen Thi Thang and 586 Hoang Thi Phuong and reviewed and edited by Tran Thi Mai Oanh. GN is the guarantor of the 587 paper. All authors read and approved the final manuscript. 
588 Acknowledgements The authors acknowledge financial and technical support for the research

589 project from the WHO Kobe Centre. We thank Megumi Rosenberg and other staff members of 590 the Centre for their technical support and comments on the overall study report and this 591 manuscript. The authors also acknowledge the staff and research team at the Health Strategy 592 and Policy Institute for their important contributions to this study. The authors also thank the 593 local health authorities, local health workers and the participants for their time and contributions 594 to the survey. 


\section{References}

599 1. United Nations DoE, Social Affairs PD. World Population Ageing 2015. New York: United Nations 6002015.

601 2. Maestas N, Mullen KJ, Powell D. The effect of population aging on economic growth, the labor 602 force and productivity. National Bureau of Economic Research; 2016.

603 3. Macinko J, Cristina Drumond Andrade F, Bof de Andrade F, Lima-Costa MF. Universal Health 604 Coverage: Are Older Adults Being Left Behind? Evidence From Aging Cohorts In Twenty-Three Countries: 605 Study examines access to care, use, catastrophic expenditures, and other factors among several aging 606 cohorts in twenty-three countries. Health Affairs. 2020;39(11):1951-60.

607 4. Wagstaff A, Eozenou P, Smitz M. Out-of-Pocket Expenditures on Health: A Global Stocktake. The 608 World Bank Research Observer. 2020;35(2):123-57.

609 5. United Nations. World Population Prospects 2019. Department of Economic and Social Affairs, 610 United Nations; 2019.

611 6. Institute of Social and Medical Studies. Viet Nam Aging Survey 2011: The key findings. Hanoi; 6122012.

613 7. Roth GA, Abate D, Abate KH, Abay SM, Abbafati C, Abbasi N, et al. Global, regional, and national 614 age-sex-specific mortality for 282 causes of death in 195 countries and territories, 1980-2017: a systematic 615 analysis for the Global Burden of Disease Study 2017. The Lancet. 2018;392(10159):1736-88.

616 8. Vietnam Ministry of Health. Health Statistics Yearbook 2018. Hanoi2019.

617 9. Ministry of Health, World Health Organization. Vietnam 2017 National Health Accounts. Hanoi: 618 Ministry of Health; 2020.

619 10. Minh HV, Kim Phuong NT, Saksena P, James CD, Xu K. Financial burden of household out-of pocket 620 health expenditure in Viet Nam: Findings from the National Living Standard Survey 2002-2010. Social 621 science \& medicine (1982). 2013;96:258-63.

622 11. Mwangi J, Kulane A, Le Van H. Chronic diseases among the elderly in a rural Vietnam: Prevalence, 623 associated socio-demographic factors and healthcare expenditures. International Journal for Equity in 624 Health. 2015;14(134).

625 12. Borson S, Scanlan JM, Chen P, Ganguli M. The Mini-Cog as a screen for dementia: validation in a 626 population-based sample. Journal of the American Geriatrics Society. 2003;51(10):1451-4.

627 13. General Statistics Office of Vietnam. Completed results of the 2019 Viet Nam Population and 628 Housing Census. Hanoi: Statistical Publishing House; 2020.

629 14. General Statistics Office of Vietnam. Health Statistics Yearbook 2018. Hanoi: Statistical Publishing 630 House; 2019.

631 15. Van Doorslaer E, O'Donnell O, Rannan-Eliya RP, Somanathan A, Adhikari SR, Garg CC, et al. 632 Catastrophic payments for health care in Asia. Health Economics. 2007;16(11):1159-84.

633 16. Flores G, Krishnakumar J, O'Donnell O, van Doorslaer E. Coping with health-care costs: 634 Implications for the measurement of catastrophic expenditures and poverty. Health Economics. 635 2008;17(12):1393-412.

636 17. Arsenijevic J, Pavlova M, Rechel B, Groot W. Catastrophic health care expenditure among older 637 people with chronic diseases in 15 European countries. PLoS ONE. 2016;11(7):e0157765. 
18. Kruk ME, Goldmann E, Galea S. Borrowing and selling to pay for health care in low- and middleincome countries. Health Aff (Millwood). 2009;28(4):1056-66.

640 19. O'Donnell O, Doorslaer Ev, Wagstaff A, Lindelow M. Analyzing health equity using household 641 survey data : A guide to techniques and their implementation. Washington, DC: World Bank Institute; 6422008.

643 20. Xu K. Distribution of health paymentsand catastrophic expenditures: Methodology. Geneva: 644 Department of Health System Financing, World Health Organization; 2005.

645 21. World Health Organization. Monitoring sustainable development goals [Available from: https://www.who.int/health financing/topics/financial-protection/monitoring-sdg/en/.

647 22. Filmer D, Pritchett LH. Estimating wealth effects without expenditure data--or tears: an 648 application to educational enrollments in states of India. Demography. 2001;38(1):115-32.

649 23. Rutstein SO. The DHS wealth index: Approaches for rural and urban areas. Calverton, Maryland, 650 USA: Macro International; 2008.

651 24. Giang NH, Oanh TTM, Anh Tuan K, Hong Van P, Jayasuriya R. Is Health Insurance Associated with 652 Health Service Utilization and Economic Burden of Non-Communicable Diseases on Households in 653 Vietnam? Health Systems \& Reform. 2020;6(1):e1619065.

654 25. Limwattananon S, Tangcharoensathien V, Prakongsai P. Catastrophic and poverty impacts of 655 health payments: Results from national household surveys in Thailand. Bulletin of the World Health 656 Organization. 2007;85(8):600-6.

657 26. Ha NTH, Berman P, Larsen U. Household utilization and expenditure on private and public health 658 services in Vietnam. Health Policy and Planning. 2002;17(1):61-70.

659 27. Anup K, Engelgau M, Mahal A. The household-level economic burden of heart disease in India. 660 Tropical Medicine and International Health. 2014;19(5):581-91.

661 28. Wagstaff A, Doorslaer Ev. Catastrophe and impoverishment in paying for health care: With 662 applications to Vietnam 1993-1998. Health Economics. 2003;12(11):921-33.

663 29. Sanjay. K. Mohanty, Chauhan RK, Mazumdar S, Srivastava A. Out-of-pocket expenditure on health 664 care among elderly and nonelderly households in India.

665 30. Liu S, Coyte PC, Fu M, Zhang Q. Measurement and determinants of catastrophic health 666 expenditure among elderly households in China using longitudinal data from the CHARLS. International 667 Journal for Equity in Health. 2021;20(1):62.

668 31. Adisa O. Investigating determinants of catastrophic health spending among poorly insured elderly 669 households in urban Nigeria. International Journal for Equity in Health. 2015;14(1):1-11.

670 32. Opondo EM, Oleche MO. Out-Of-Pocket Health Expenditure Among the Elderly in Kenya. Global 671 Journal of Health Science. 2020;12.

672 33. Thuy NK, Oanh Thi Hai K, Ma SG, Duc Cuong P, Giang Thi Hong K, Ruger JP. Coping with health 673 care expenses among poor households: Evidence from a rural commune in Vietnam. Social Science \& 674 Medicine. 2012;74(5):724-33.

675 34. Kruk ME, Goldmann E, Galea S. Borrowing And Selling To Pay For Health Care In Low- And Middle676 Income Countries. Health Affairs. 2009;28(4):1056-66. 
35. Segall M, Tipping G, Lucas H, Dung $T$, Tam N, Vinh D, et al. Economic transition should come with 678 a health warning: The case of Vietnam. Journal of Epidemiology and Community Health. 2002;56(7):497679505.

680 36. Sepehri A, Chernomas R, Akram-Lodhi AH. If they get sick, they are in trouble: Health care 681 restructuring, user charges, and equity in Vietnam. International Journal of Health Services. 682 2003;33(1):137-61.

683 37. Daivadanam M, Thankappan KR, Sarma PS, Harikrishnan S. Catastrophic health expenditure \& 684 coping strategies associated with acute coronary syndrome in Kerala, India. The Indian Journal of Medical 685 Research. 2012;136(4):585-92.

686 38. Htet S, Alam K, Mahal A. Economic burden of chronic conditions among households in Myanmar: 687 The case of angina and asthma. Health Policy and Planning. 2014.

688 39. Saksena P, Xu K, Evans DB. Impact of out-of-pocket payments for treatment of non-communicable diseases in developing countries: a review of literature. Geneva: World Health Organization; 2011.

690 40. Huffman MD, Rao KD, Pichon-Riviere A, Zhao D, Harikrishnan S, Ramaiya K, et al. A cross-sectional 691 study of the microeconomic impact of cardiovascular disease hospitalization in four Low- and Middle692 Income Countries. PLoS ONE. 2011;6(6):e20821.

693 41. Rittirong J, Prasartkul P, Rindfuss RR. From whom do older persons prefer support? The case of 694 rural Thailand. J Aging Stud. 2014;31:171-81.

695 42. Shamsikhani S, Ahmadi F, Kazemnejad A, Vaismoradi M. Typology of Family Support in Home Care for Iranian Older People: A Qualitative Study. Int J Environ Res Public Health. 2021;18(12).

697 43. Wagstaff A. The economic consequences of health shocks: Evidence from Vietnam. Journal of 698 Health Economics. 2007;26(1):82-100.

699 44. Hesamzadeh A, Dalvandi A, Bagher Maddah S, Fallahi Khoshknab M, Ahmadi F, Mosavi Arfa N. 700 Family caregivers' experience of activities of daily living handling in older adult with stroke: a qualitative 701 research in the Iranian context. Scand J Caring Sci. 2017;31(3):515-26.

702 45. Engelgau MM, Karan A, Mahal A. The economic impact of Non-Communicable Diseases on 703 households in India. Globalization and Health. 2012;8(9).

704 46. Wagstaff $A$, Lindelow $M$, Jun $G$, Ling $X$, Juncheng $Q$. Extending health insurance to the rural population: an impact evaluation of China's new cooperative medical scheme. Journal of health economics. 2009;28(1):1-19.

47. Vietnam Ministry of Health, Health Partnership Group. Joint Annual Health Review 2011: Strengthening management capacity and reforming health financing to implement the five-year health sector plan 2011-2015. Hanoi: Vietnam Ministry of Health; 2011.

48. Etienne C, Asamoa-Baah A, Evans DB. Health systems financing: the path to universal coverage. Geneva: World Health Organization; 2010.

49. Kien VD, Minh HV, Giang KB, Dao A, Tuan KT, Ng N. Socioeconomic inequalities in catastrophic health expenditure and impoverishment associated with non-communicable diseases in urban Hanoi, Vietnam. International Journal for Equity in Health. 2016;15:169.

50. Kien VD, Minh HV, Ngoc NB, Phuong TB, Ngan TT, Quam MB. Inequalities in household catastrophic health expenditure and impoverishment associated with noncommunicable diseases in Chi Linh, Hai Duong, Vietnam. Asia Pacific Journal of Public Health. 2017;29(5_suppl):35S-44S. 
51. Yip W, Hsiao WC. Non-evidence-based policy: How effective is China's new cooperative medical scheme in reducing medical impoverishment? Social Science \& Medicine. 2009;68(2):201-9.

720 52. Kimman M, Jan S, Yip CH, Thabrany H, Peters SA, Bhoo-Pathy N, et al. Catastrophic health 721 expenditure and 12-month mortality associated with cancer in Southeast Asia: Results from a longitudinal 722 study in eight countries. BMC Medicine. 2015;13 (1) (190).

723 53. Wang Z, Li X, Chen M. Catastrophic health expenditures and its inequality in elderly households 724 with chronic disease patients in China. International Journal for Equity in Health. 2015;14(8).

725 54. Zhao S-w, Zhang X-y, Dai W, Ding Y-x, Chen J-y, Fang P-q. Effect of the catastrophic medical insurance on household catastrophic health expenditure: evidence from China. Gaceta Sanitaria. 2020;34(4):370-6.

55. Wang $Q$, Liu H, Lu ZX, Luo Q, Liu JA. Role of the new rural cooperative medical system in alleviating catastrophic medical payments for hypertension, stroke and coronary heart disease in poor rural areas of China. BMC Public Health. 2014;14(907).

731 56. Somanathan A, Tandon A, Dao HL, Hurt KL, Fuenzalida-Puelma HL. Moving toward Universal Coverage of Social Health Insurance in Vietnam: Assessment and Options. Washington DC: World Bank; 2014.

734 57. Vietnam Ministry of Health, Health Partnership Group. Joint Annual Health Review 2013: Towards 735 Universal Health Coverage. Hanoi: Ministry of Health; 2013.

736 58. Du J, Yang X, Chen M, Wang Z. Socioeconomic determinants of out-of-pocket pharmaceutical expenditure among middle-aged and elderly adults based on the China Health and Retirement Longitudinal Survey. BMJ Open. 2019;9(7):e024936.

59. Tangcharoensathien V, Patcharanarumol W, Ir P, Aljunid SM, Mukti AG, Akkhavong K, et al. Health-financing reforms in southeast Asia: challenges in achieving universal coverage. Lancet. 2011;377(9768):863-73.

60. Mendis S, Al Bashir I, Dissanayake L, Varghese C, Fadhil I, Marhe E, et al. Gaps in capacity in primary care in low-resource settings for implementation of essential noncommunicable disease interventions. Int 744 J Hypertens. 2012;2012:584041.

61. Minh HV, Do YK, Bautista MA, Anh TT. Describing the primary care system capacity for the prevention and management of non-communicable diseases in rural Vietnam. The International journal of health planning and management. 2014;29(2):e159-73.

748 62. Thi Thuy Nga N, Thi My Anh B, Nguyen Ngoc N, Minh Diem D, Duy Kien V, Bich Phuong T, et al. Capacity of Commune Health Stations in Chi Linh District, Hai Duong Province, for Prevention and Control of Noncommunicable Diseases. Asia Pacific Journal of Public Health. 2017;29(5_suppl):94S-101S.

63. Duong DB, Minh HV, Ngo LH, Ellner AL. Readiness, Availability and Utilization of Rural Vietnamese Health Facilities for Community Based Primary Care of Non-communicable Diseases: A CrossSectional Survey of 3 Provinces in Northern Vietnam. Int J Health Policy Manag. 2019;8(3):150-7. expenditure in an urban city: Seven years after universal coverage policy in Thailand. Southeast Asian Journal of Tropical Medicine and Public Health. 2013;44(1):124-36. 
66. Jing Z, Li J, Fu PP, Wang Y, Yuan Y, Zhao D, et al. Catastrophic health expenditure among single empty-nest elderly with multimorbidity in rural Shandong, China: the effect of co-occurrence of frailty. International Journal for Equity in Health. 2021;20(1):23.

763 67. Minh HV, Bach TX. Assessing the household financial burden associated with the chronic noncommunicable diseases in a rural district of Vietnam. Global Health Action. 2012;5(18892).

68. Ramachandran A, Ramachandran S, Snehalatha C, Augustine C, Murugesan N, Viswanathan V, et al. Increasing Expenditure on Health Care Incurred by Diabetic Subjects in a Developing Country: A study from India. Diabetes care. 2007;30(2):252-6.

768 69. Teng H, Cao Z, Liu J, Liu P, Hua W, Yang Y, et al. Health status and burden of health care costs among urban elderly in China. (Special Issue: Public health research in China: some recent findings and implications.). Asia Pacific Journal of Public Health. 2015;27(2 Suppl).

70. Lee JT, Hamid F, Pati S, Atun R, Millett C. Impact of noncommunicable disease multimorbidity on healthcare utilisation and out-of-pocket expenditures in middle-income countries: Cross sectional 773 analysis. PLoS ONE. 2015;10(7).

774 71. Aji B, Yamamoto SS, Sauerborn R. The economic impact of the insured patients with severe chronic and acute illnesses: a qualitative approach. Glob Health Action. 2014;7(22526).

776 72. Nortey ST, Aryeetey GC, Aikins M, Amendah D, Nonvignon J. Economic burden of family caregiving 777 for elderly population in southern Ghana: the case of a peri-urban district. International journal for equity 778 in health. 2017;16(1):16-.

779 73. Kaur P, Kwatra G, Kaur R, Pandian JD. Cost of stroke in low and middle income countries: a 780 systematic review. International journal of stroke : official journal of the International Stroke Society. 781 2014;9(6):678-82.

782 74. El-Sayed AM, Palma A, Freedman LP, Kruk ME. Does health insurance mitigate inequities in non783 communicable disease treatment? Evidence from 48 low- and middle-income countries. Health Policy. 784 2015;119(9):1164-75.

785 75. Gotsadze G, Bennett S, Ranson K, Gzirishvili D. Health care-seeking behaviour and out-of-pocket 786 payments in Tbilisi, Georgia. Health Policy and Planning. 2005;20(4):232-42.

787 76. Moreno-Serra R, Millett C, Smith PC. Towards Improved Measurement of Financial Protection in 788 Health. PLOS Medicine. 2011;8(9):e1001087.

789 77. Lu C, Chin B, Li G, Murray CJL. Limitations of methods for measuring out-of-pocket and 790 catastrophic private health expenditures. Bulletin of the World Health Organization. 2009;87(3):238-44.

791 78. Yip W, Hsiao W. China's health care reform: A tentative assessment. China Economic Review. 792 2009;20(4):613-9. 
Table 1. Descriptive characteristics of households that included at least one member $\geq 60$ years, Viet Nam

\begin{tabular}{|c|c|c|}
\hline \multirow{2}{*}{ Variables } & \multicolumn{2}{|c|}{ Total $(N=1477)$} \\
\hline & $n$ & $\%$ or mean (SD) \\
\hline \multicolumn{3}{|l|}{ Household features } \\
\hline \multicolumn{3}{|l|}{ Urban versus rural } \\
\hline Urban & 720 & $48.7 \%$ \\
\hline Rural & 757 & $51.3 \%$ \\
\hline \multicolumn{3}{|l|}{ Province } \\
\hline Thanh Hoa & 498 & $33.7 \%$ \\
\hline Tien Giang & 484 & $32.8 \%$ \\
\hline Yen Bai & 495 & $33.5 \%$ \\
\hline No. of people in households (household size) & 1477 & $3.2(1.8)$ \\
\hline \multicolumn{3}{|l|}{ Children $<6$ years in the household } \\
\hline No & 1246 & $84.4 \%$ \\
\hline Yes & 231 & $15.6 \%$ \\
\hline \multicolumn{3}{|l|}{ No. of people aged $\geq 60$ years in the household } \\
\hline 1 person & 642 & $43.5 \%$ \\
\hline$\geq 2$ persons & 835 & $56.5 \%$ \\
\hline \multicolumn{3}{|l|}{ Household composition } \\
\hline Multigenerational & 853 & $57.8 \%$ \\
\hline Only older generation & 624 & $42.2 \%$ \\
\hline \multicolumn{3}{|l|}{ Health insurance status } \\
\hline Not fully insured & 174 & $11.8 \%$ \\
\hline Fully insured & 1303 & $88.2 \%$ \\
\hline \multicolumn{3}{|l|}{ Wealth level (quintile) } \\
\hline Poorest & 296 & $20.0 \%$ \\
\hline Poor & 295 & $20.0 \%$ \\
\hline Middle & 296 & $20.0 \%$ \\
\hline Rich & 295 & $20.0 \%$ \\
\hline Richest & 295 & $20.0 \%$ \\
\hline \multicolumn{3}{|l|}{ Head of household } \\
\hline \multicolumn{3}{|l|}{ Aged $\geq 60$ years } \\
\hline No & 110 & $7.4 \%$ \\
\hline Yes & 1367 & $92.6 \%$ \\
\hline \multicolumn{3}{|l|}{ Sex } \\
\hline Male & 784 & $53.1 \%$ \\
\hline Female & 693 & $46.9 \%$ \\
\hline \multicolumn{3}{|l|}{ Ethnicity } \\
\hline Kinh & 1449 & $98.7 \%$ \\
\hline Ethnic minority & 19 & $1.3 \%$ \\
\hline \multicolumn{3}{|l|}{ Educational level } \\
\hline Elementary or less & 543 & $36.8 \%$ \\
\hline
\end{tabular}




\begin{tabular}{lcc}
\hline \multirow{2}{*}{ Variables } & \multicolumn{2}{c}{ Total (N= 1477) } \\
\cline { 2 - 3 } & $\boldsymbol{n}$ & \% or mean (SD) \\
\hline Secondary school & 419 & $28.4 \%$ \\
High school or higher & 514 & $34.8 \%$ \\
Current occupational status & & \\
$\quad$ Employed & 490 & $33.3 \%$ \\
$\quad$ Pensioner & 479 & $32.6 \%$ \\
$\quad$ Unemployed & 502 & $34.1 \%$ \\
Health care for older members & & \\
Comorbidities & & \\
$\quad$ No NCD & 304 & $20.6 \%$ \\
1 NCD & 551 & $37.3 \%$ \\
$\quad \geq 2$ NCDs & 622 & $42.1 \%$ \\
Mean (SD) no. monthly outpatient visits & & \\
Primary health care facilities & 1477 & $0.46(0.86)$ \\
Tertiary health facilities & 1477 & $0.36(0.84)$ \\
Private health facilities & 1477 & $0.13(0.51)$ \\
Mean (SD) no. inpatient admissions (previous & & \\
12 months) & & \\
District hospitals & 1477 & $0.09(0.43)$ \\
Tertiary hospitals & 1477 & $0.19(0.70)$ \\
Private hospitals & 1477 & $0.02(0.18)$ \\
\hline
\end{tabular}

NCD: noncommunicable disease; SD: standard deviation. 
Table 2. Financial burden borne by households that included people aged $\geq 60$ years, Viet Nam

Out-of-pocket health expenditure

Total

$(N=1477)$

Mean (minimum-maximum) total household health expenditure in 1000 Vietnamese Dong

$7989(0-108280)$

Mean (minimum-maximum) total household health expenditure for older people in 1000 Vietnamese Dong

$7378(0-106910)$

$\%$ total household health expenditure spent on older people

86.3

$\%$ (no.) of households with health expenditure exceeding $40 \%$ of capacity to pay

$8.6(127)$

$\%$ (no.) of households with health expenditure exceeding $40 \%$ of capacity to pay when health spending for older members is excluded

$1.96(29)$

$\%$ (no.) of households with health expenditure exceeding $10 \%$ of total household expenditure

$\%$ (no.) of households with health expenditure exceeding $25 \%$ of total household expenditure

$\%$ (no.) of households facing financial distress due to spending for outpatient services

$\%$ (no.) of households facing financial distress due to spending for inpatient services

$5.4(79)$

$\%$ (no.) of households facing financial distress due to spending for health services

$12.3(181)$ 
Table 3. Households that include people $\geq 60$ years with catastrophic health expenditure and financial distress, by household covariates, Viet Nam ${ }^{\mathrm{a}}$

\begin{tabular}{|c|c|c|c|c|c|c|}
\hline \multirow{3}{*}{ Variable } & \multicolumn{4}{|c|}{ Catastrophic health expenditure definition ${ }^{\text {b }}$} & \multirow{2}{*}{\multicolumn{2}{|c|}{ Financial distress }} \\
\hline & \multicolumn{2}{|c|}{ World Health Organization } & \multicolumn{2}{|c|}{$\begin{array}{c}\text { Sustainable Development } \\
\text { Goals }\end{array}$} & & \\
\hline & $\begin{array}{c}\text { Yes } \\
(n=126)\end{array}$ & $\begin{array}{c}\text { No } \\
(n=1351)\end{array}$ & $\begin{array}{c}\text { Yes } \\
(n=111)\end{array}$ & $\begin{array}{c}\text { No } \\
(n=1366)\end{array}$ & $\begin{array}{c}\text { Yes } \\
(n=181)\end{array}$ & $\begin{array}{c}\text { No } \\
(n=1296)\end{array}$ \\
\hline \multicolumn{7}{|l|}{ Household features } \\
\hline \multicolumn{7}{|l|}{ Urban versus rural } \\
\hline Urban & $54(7.5)$ & $666(92.5)$ & $46(6.4)$ & $674(93.6)$ & $80(11.1)$ & $640(88.9)$ \\
\hline Rural & $72(9.5)$ & $685(90.5)$ & $65(8.6)$ & $692(91.4)$ & $101(13.3)$ & $656(86.7)$ \\
\hline Province & $* * *$ & & $* * *$ & & $*$ & \\
\hline Thanh Hoa & $35(7.0)$ & $463(93.0)$ & $38(7.6)$ & $460(92.4)$ & $51(10.2)$ & $447(89.8)$ \\
\hline Tien Giang & $9(1.9)$ & $475(98.1)$ & $8(1.7)$ & $476(98.3)$ & $55(11.4)$ & $429(88.6)$ \\
\hline Yen Bai & $82(16.6)$ & $413(83.4)$ & $65(13.1)$ & $430(86.9)$ & $75(15.2)$ & $420(84.8)$ \\
\hline $\begin{array}{l}\text { Mean (SD) no. of people in } \\
\text { household }\end{array}$ & $1.6(0.5)^{* * *}$ & $3.4(1.9)$ & $2.0(1.1)^{* * *}$ & $3.3(1.9)$ & $3.0(1.8)^{*}$ & $3.3(1.9)$ \\
\hline Children $<6$ years & $* * *$ & & $* * *$ & & & \\
\hline No & $126(10.1)$ & 1120 (89.9) & $106(8.5)$ & 1140 (91.5) & $157(12.6)$ & $1089(87.4)$ \\
\hline Yes & $0(0.0)$ & $231(100.0)$ & $5(2.2)$ & $226(97.8)$ & $24(10.4)$ & 207 (89.6) \\
\hline \multicolumn{7}{|l|}{$\begin{array}{l}\text { People aged } \geq 60 \text { years in the } \\
\text { household }\end{array}$} \\
\hline 1 person & $57(8.9)$ & $585(91.1)$ & $52(8.1)$ & 590 (91.9) & $84(13.1)$ & $558(86.9)$ \\
\hline $2+$ persons & $69(8.3)$ & 766 (91.7) & $59(7.1)$ & 776 (92.9) & $97(11.6)$ & $738(88.4)$ \\
\hline Household composition & $* * *$ & & $* * *$ & & $*$ & \\
\hline Multigenerational & $8(0.9)$ & 845 (99.1) & 25 (2.9) & $828(97.1)$ & $92(10.8)$ & $761(89.2)$ \\
\hline Only older generation & $118(18.9)$ & $506(81.1)$ & $86(13.8)$ & $538(86.2)$ & $89(14.3)$ & $535(85.7)$ \\
\hline Health insurance status & $* * *$ & & $* * *$ & & & \\
\hline Not fully insured & $4(2.3)$ & $170(97.7)$ & $3(1.7)$ & $171(98.3)$ & 19 (10.9) & $155(89.1)$ \\
\hline Fully insured & $122(9.4)$ & $1181(90.6)$ & $108(8.3)$ & 1195 (91.7) & $162(12.4)$ & $1141(87.6)$ \\
\hline Wealth level (quintile) & & & & & $*$ & \\
\hline Poorest & $22(7.4)$ & $274(92.6)$ & $14(4.7)$ & $282(95.3)$ & 44 (14.9) & $252(85.1)$ \\
\hline Poor & $29(9.8)$ & $266(90.2)$ & $25(8.5)$ & $270(91.5)$ & 44 (14.9) & $251(85.1)$ \\
\hline Middle & $36(12.2)$ & $260(87.8)$ & $32(10.8)$ & $264(89.2)$ & $40(13.5)$ & $256(86.5)$ \\
\hline Rich & $18(6.1)$ & 277 (93.9) & $19(6.4)$ & $276(93.6)$ & $25(8.5)$ & 270 (91.5) \\
\hline Richest & $21(7.1)$ & 274 (92.9) & $21(7.1)$ & $274(92.9)$ & $28(9.5)$ & 267 (90.5) \\
\hline \multicolumn{7}{|l|}{ Head of household } \\
\hline Aged $\geq 60$ years & $*$ & & & & & \\
\hline No & $3(2.7)$ & 107 (97.3) & $9(8.2)$ & $101(91.8)$ & $11(10.0)$ & $99(90.0)$ \\
\hline Yes & $123(9.0)$ & $1,244(91.0)$ & $102(7.5)$ & $1,265(92.5)$ & $170(12.4)$ & $1,197(87.6)$ \\
\hline \multicolumn{7}{|l|}{ Sex } \\
\hline Male & $69(8.8)$ & 715 (91.2) & $63(8.0)$ & $721(92.0)$ & 93 (11.9) & $691(88.1)$ \\
\hline Female & $57(8.2)$ & $636(91.8)$ & $48(6.9)$ & $645(93.1)$ & $88(12.7)$ & $605(87.3)$ \\
\hline Ethnicity & & & $*$ & & & \\
\hline Kinh & $124(8.6)$ & 1,325 (91.4) & $107(7.4)$ & $1,342(92.6)$ & $176(12.1)$ & $1,273(87.9)$ \\
\hline
\end{tabular}




\begin{tabular}{|c|c|c|c|c|c|c|}
\hline \multirow{3}{*}{ Variable } & \multicolumn{4}{|c|}{ Catastrophic health expenditure definition $^{b}$} & \multirow{2}{*}{\multicolumn{2}{|c|}{ Financial distress }} \\
\hline & \multicolumn{2}{|c|}{ World Health Organization } & \multicolumn{2}{|c|}{$\begin{array}{l}\text { Sustainable Development } \\
\text { Goals }\end{array}$} & & \\
\hline & $\begin{array}{c}\text { Yes } \\
(n=126)\end{array}$ & $\begin{array}{c}\text { No } \\
(n=1351)\end{array}$ & $\begin{array}{c}\text { Yes } \\
(n=111)\end{array}$ & $\begin{array}{c}\text { No } \\
(n=1366)\end{array}$ & $\begin{array}{c}\text { Yes } \\
(n=181)\end{array}$ & $\begin{array}{c}\text { No } \\
(n=1296)\end{array}$ \\
\hline Ethnic minority & $2(10.5)$ & $17(89.5)$ & $4(21.1)$ & $15(78.9)$ & $5(26.3)$ & $14(73.7)$ \\
\hline Educational level & $* *$ & & $* * *$ & & $*$ & \\
\hline Elementary or less & $29(5.3)$ & $514(94.7)$ & $17(3.1)$ & $526(96.9)$ & $76(14.0)$ & $467(86.0)$ \\
\hline Secondary school & $48(11.5)$ & $371(88.5)$ & $50(11.9)$ & $369(88.1)$ & $59(14.1)$ & 360 (85.9) \\
\hline High school or higher & $49(9.5)$ & $465(90.5)$ & $44(8.6)$ & $470(91.4)$ & $46(8.9)$ & $468(91.1)$ \\
\hline Current occupational status & $*$ & & $*$ & & $* * *$ & \\
\hline Employed & $33(6.7)$ & $457(93.3)$ & $34(6.9)$ & $456(93.1)$ & $51(10.4)$ & 439 (89.6) \\
\hline Pensioner & $53(11.1)$ & $426(88.9)$ & $47(9.8)$ & $432(90.2)$ & $39(8.1)$ & 440 (91.9) \\
\hline Unemployed & $38(7.6)$ & $464(92.4)$ & $28(5.6)$ & $474(94.4)$ & $88(17.5)$ & $414(82.5)$ \\
\hline \multicolumn{7}{|l|}{ Health care for older members } \\
\hline Comorbidities & $* * *$ & & $* * *$ & & $* * *$ & \\
\hline No NCD & $8(2.6)$ & $296(97.4)$ & $6(2.0)$ & $298(98.0)$ & $6(2.0)$ & $298(98.0)$ \\
\hline $1 \mathrm{NCD}$ & $49(8.9)$ & $502(91.1)$ & $36(6.5)$ & $515(93.5)$ & $66(12.0)$ & $485(88.0)$ \\
\hline$\geq 2$ NCDs & $69(11.1)$ & $553(88.9)$ & $69(11.1)$ & $553(88.9)$ & $109(17.5)$ & $513(82.5)$ \\
\hline \multicolumn{7}{|c|}{ Mean (SD) no. monthly outpatient visits } \\
\hline Primary health care facilities & $0.50(0.80)$ & $0.46(0.86)$ & $0.58(1.17)$ & $0.45(0.82)$ & $0.82(1.06)^{* * *}$ & $0.41(0.81)$ \\
\hline Tertiary facilities & $0.47(0.98)$ & $0.35(0.83)$ & $0.54(1.06)^{*}$ & $0.35(0.82)$ & $0.54(1.04)^{* *}$ & $0.34(0.81)$ \\
\hline Private health facilities & $0.23(0.67)^{*}$ & $0.13(0.49)$ & $0.23(0.68)^{*}$ & $0.13(0.49)$ & $0.23(0.65)^{* *}$ & $0.12(0.48)$ \\
\hline \multicolumn{7}{|c|}{ Mean (SD) no. inpatient admissions (previous 12 months) } \\
\hline District hospitals & $0.14(0.41)$ & $0.09(0.43)$ & $0.19(0.56)^{*}$ & $0.08(0.41)$ & $0.26(0.62)^{* * *}$ & $0.07(0.39)$ \\
\hline Tertiary hospitals & $0.34(0.70)^{*}$ & $0.17(0.70)$ & $0.37(0.78)^{* *}$ & $0.17(0.69)$ & $0.48(0.97)^{* * *}$ & $0.15(0.64)$ \\
\hline Private hospitals & $0.04(0.23)$ & $0.02(0.18)$ & $0.07(0.29)^{* *}$ & $0.02(0.17)$ & $0.04(0.19)$ & $0.02(0.18)$ \\
\hline $\begin{array}{l}\text { NCD: noncommunica } \\
\text { a Values are number } \\
{ }^{b} \text { The World Health } \mathrm{O} \\
\text { spending for a house } \\
\text { total household expe }\end{array}$ & $\begin{array}{l}\text { disease; SD: sta } \\
\text { unless otherwis } \\
\text { nization defines } \\
\text { d, whereas Sust } \\
\text { ture. }\end{array}$ & $\begin{array}{l}\text { dard deviation } \\
\text { indicated. } \\
\text { catastrophic he } \\
\text { inable Develop }\end{array}$ & $\begin{array}{l}*: P<0.05 ; * *: P \\
\text { Ith expenditure } \\
\text { ent Goal indicat }\end{array}$ & $\begin{array}{l}0.01 ;{ }^{* *}: P< \\
\text { a threshold of } \\
3.8 .2 \text { defines }\end{array}$ & $\begin{array}{l}01 . \\
\% \text { of non-food } \\
\text { a } 10 \% \text { thresho }\end{array}$ & \\
\hline
\end{tabular}


Table 4. Logistic regression models predicting the determinants of catastrophic health expenditure and financial distress among households with people $\geq 60$ years, Viet Nam

\begin{tabular}{|c|c|c|c|c|}
\hline \multirow{2}{*}{ Variable } & \multicolumn{2}{|c|}{$\begin{array}{c}\text { Catastrophic health expenditure } \\
\text { (World Health Organization's } \\
\text { definition) }\end{array}$} & \multicolumn{2}{|c|}{ Financial distress } \\
\hline & $\begin{array}{l}\text { Adjusted odds ratio } \\
\qquad(95 \% \mathrm{Cl})\end{array}$ & $\boldsymbol{P}$ & $\begin{array}{l}\text { Adjusted odds } \\
\text { ratio } \\
(95 \% \mathrm{Cl})\end{array}$ & $\boldsymbol{P}$ \\
\hline Household size & $0.18(0.12$ to 0.27$)$ & 0.000 & 0.89 (0.81 to 0.99$)$ & 0.024 \\
\hline \multicolumn{5}{|c|}{ Head of household's occupational status } \\
\hline Unemployed & $\mathrm{NA}$ & $N A$ & - & \\
\hline Employed & INA & INA & $0.70(0.47$ to 1.04$)$ & 0.079 \\
\hline Pensioner & & & $0.27(0.17$ to 0.44$)$ & 0.000 \\
\hline \multicolumn{5}{|l|}{ Wealth level (quintile) } \\
\hline Poorest & - & - & \multirow{5}{*}{ NA } & \multirow{5}{*}{ NA } \\
\hline Poor & 3.79 (1.86 to 7.70$)$ & 0.000 & & \\
\hline Middle & 7.89 (3.79 to 16.4$)$ & 0.000 & & \\
\hline Rich & $2.11(0.92$ to 4.86$)$ & 0.070 & & \\
\hline Richest & $2.84(1.27$ to 6.30$)$ & 0.010 & & \\
\hline \multicolumn{5}{|c|}{ Older household members' comorbidities } \\
\hline No NCD & - & - & - & - \\
\hline $1 \mathrm{NCD}$ & $5.16(2.27$ to 11.7$)$ & 0.000 & $4.75(2.00$ to 11.3$)$ & 0.000 \\
\hline$\geq 2 \mathrm{NCDs}$ & 7.05 (3.11 to 16.0$)$ & 0.000 & $4.72(1.92$ to 11.6$)$ & 0.001 \\
\hline \multicolumn{5}{|c|}{ Mean no. monthly outpatient visits by older household members } \\
\hline Primary health care facilities & NA & NA & 1.55 (1.26 to 1.89$)$ & 0.000 \\
\hline Tertiary health facilities & NA & NA & $1.39(1.13$ to 1.70$)$ & 0.002 \\
\hline Private health facilities & $2.13(1.44-3.18)$ & 0.000 & 1.47 (1.09 to 1.98$)$ & 0.012 \\
\hline \multicolumn{5}{|c|}{ Mean no. inpatient admissions for older household members (previous 12 months) } \\
\hline District hospitals & NA & NA & 1.72 (1.27 to 2.34$)$ & 0.000 \\
\hline Tertiary hospitals & $1.34(1.06$ to 1.70$)$ & 0.015 & 1.54 (1.27 to 1.87$)$ & 0.000 \\
\hline \multicolumn{5}{|l|}{ Urban versus rural } \\
\hline Urban & - & - & NA & NA \\
\hline Rural & 2.06 (1.27 to 3.39$)$ & 0.004 & & \\
\hline \multicolumn{5}{|l|}{ Province } \\
\hline Tien Giang & - & - & - & - \\
\hline Thanh Hoa & 5.05 (2.10 to 12.2$)$ & 0.000 & 1.51 (0.95 to 2.41$)$ & 0.085 \\
\hline Yen Bai & $13.7(5.77$ to 32.4$)$ & 0.000 & $2.00(1.27$ to 3.17$)$ & 0.003 \\
\hline
\end{tabular}

